\title{
Inferring the ecology of willow warblers during their winter moult by sequential stable isotope analyses of remiges
}

\author{
Keith W. Larson, Miriam Liedvogel, Staffan Bensch, Susanne Åkesson, \\ Leonard I. Wassenaar and Keith A. Hobson
}

K.W. Larson (keith.w.larson@gmail.com), M. Liedvogel, S. Bensch and S. Akesson, Dept of Biology, Centre for Animal Movement Research, Ecology Building, Lund Univ., SE-223 62 Lund, Sweden. - L. I. Wassenaar and K. A. Hobson, Environment Canada, 11 Innovation Blvd., Saskatoon, SK S7N 3H5, Canada.

\begin{abstract}
We present a comparison of feather stable isotope $\left(\delta^{13} \mathrm{C}, \delta^{15} \mathrm{~N}\right)$ patterns representing the habitat and diet conditions for two subspecies of willow warblers Phylloscopus trochilus that breed in parapatry, but winter in different regions of subSaharan Africa. Previous analyses have shown that on average winter moulted innermost primaries (P1) show subspecific differences in $\delta^{15} \mathrm{~N}$ values, although individuals show substantial variation for both $\delta^{13} \mathrm{C}$ and $\delta^{15} \mathrm{~N}$ within the subspecies. We examined whether corresponding variation in the timing of the winter moult, as reflected by consistent intra-wing correlations for individual's $\delta^{13} \mathrm{C}$ and $\delta^{15} \mathrm{~N}$ values, could explain some of the previously observed isotopic variation. Further, differential subspecific adaptations to winter precipitation patterns across Africa might result in a variable degree of site fidelity or itinerancy during moult. We found no consistent trend in isotopic values from innermost to outermost primaries, thus inter-individual variation in the timing of moult does not explain the subspecific isotopic variation for P1. Patterns in wing feather $\delta^{13} \mathrm{C}$ and $\delta^{15} \mathrm{~N}$ values indicated that $41 \%$ of the individuals from both subspecies shifted their diet or habitats during winter moult. Importantly, despite well-documented itinerancy in willow warblers during the winter, $59 \%$ of the individuals had feather isotope values consistent with stable use of habitats or diets during winter moult. Repeatability analyses suggest that individuals of both subspecies initiate moult in similar habitats from year-to-year while feeding on isotopically similar diets.
\end{abstract}

The subset of population-specific phenotypic traits that characterize a migratory strategy, namely, the onset, duration, and direction of migration define the migratory phenotype, or 'migratype'. In the boreal forest of Scandinavia, the willow warbler Phylloscopus trochilus is one of the most abundant long-distance Palaearctic-Afrotropical migratory bird species (Ulfstrand and Högstedt 1976, Cramp and Brooks 1992). Two migratypes meet in Scandinavia forming a migratory divide with the southern $P$. t. trochilus wintering in west Africa and the northern $P$. $t$. acredula wintering in east to south Africa (Hedenström and Pettersson 1987, Chamberlain et al. 2000, Bensch et al. 2006). On either side of the migratory divide, the two subspecies of willow warblers show clear differences in population-specific migratory behaviour. Differences in winter-grown feather isotopic values between migratypes provide insights into adaptations and the ecology during the moulting period in Africa, an important but difficult part of the annual cycle to study in long-distance songbird migrants. Here we analyze the feather stable isotope $\left(\delta^{13} \mathrm{C}, \delta^{15} \mathrm{~N}\right)$ patterns of all primary feathers grown in the sub-Sahara African wintering areas for these two willow warblers subspecies.
For birds that moult in sub-Saharan Africa, the eastwest moisture gradient and differences in precipitation patterns north and south of the equator may make $\delta^{13} \mathrm{C}$ and $\delta^{15} \mathrm{~N}$ measurements useful indicators of moult provenance (Chamberlain et al. 2000, Evans et al. 2003, Møller and Hobson 2004, Pain et al. 2004). The willow warbler annual cycle includes two complete moults, one after breeding in Eurasia and the other while wintering in Africa (Underhill et al. 1992). If we assume that differences in feather isotope values indicate different isotopic landscapes (isoscapes) or provenance where feathers are grown, a comparison of feather isotope values between both subspecies may reveal differences in climate, habitat, and diet on their respective wintering grounds. Moreover, the $\delta^{15} \mathrm{~N}$ and $\delta^{13} \mathrm{C}$ feather isoscapes expected for Africa are diverse across the extensive wintering range of willow warblers and so we expected the isotope approach to be sensitive to potential movements of populations within Africa (Hobson et al. 2012).

We know from previous work that $\delta^{15} \mathrm{~N}$ values differ between west African wintering trochilus and east to south African wintering acredula, however there is a lot of variation within each subspecies (Chamberlain et al. 2000). Part 
of this variation could be caused by individual differences in the location, timing, and duration of their winter moult. The time span between the shedding of the innermost and outermost primary feather is at least six weeks on the winter grounds, but might be substantially longer in slower moulting individuals (Underhill et al. 1992, Bensch and Grahn 1993). If the isotopic values are found to change consistently across the wing (from lower to higher values or vice versa), part of the within-subspecies variation in isotopic values as measured for the innermost primary could be caused by a corresponding variation in the timing of moult.

When comparing the subspecies, we predict that because trochilus initiates the winter moult in west Africa well after the end of the rainy season we should see $\delta^{13} \mathrm{C}$ and $\delta^{15} \mathrm{~N}$ values that reflect increasingly arid conditions and the physiological responses to these conditions, i.e. increasing $\delta^{13} \mathrm{C}$ and $\delta^{15} \mathrm{~N}$ values from the replacement of the innermost to the outermost primary. These patterns are predicted to contrast with acredula which initiates moult in east to south Africa at the onset of the rainy season where wet conditions should result in stable or decreasing $\delta^{13} \mathrm{C}$ and $\delta^{15} \mathrm{~N}$ values across all nine primaries.

Many Palaearctic-Afrotropical migrants use an 'itinerancy' strategy on their sub-Sahara African wintering grounds, rather than being stationary or territorial (Moreau 1972, Salewski and Jones 2006). Itinerancy likely reflects the necessity to track highly seasonal resources that increase with the rainy seasons and decrease steadily after the rains end. In the case of itinerant winter residents, individuals may stay in one location to moult or change locations or shift diet in response to changes in resource availability. We know that some willow warblers likely move during their winter moult (Underhill et al. 1992), but it is not known whether this is more common among trochilus or acredula. We predict greater variability in feather $\delta^{13} \mathrm{C}$ and $\delta^{15} \mathrm{~N}$ values for trochilus as moult is protracted over two months (Underhill et al. 1992) and occurs at the end or after the end of the rainy season where conditions continuously increase in aridity (Janowiak 1988). Due to these increasingly drying conditions, trochilus moult may occur over larger isotopic gradients as they track resources following the moisture gradient southeast. In contrast, we predict the patterns of $\delta^{13} \mathrm{C}$ and $\delta^{15} \mathrm{~N}$ variability across the wing to be less in acredula as individuals might show greater site fidelity due to stable resources and moult duration being shorter.

Finally, Bensch et al. (2006) found that there is significant between-year repeatability in $\delta^{13} \mathrm{C}$ and $\delta^{15} \mathrm{~N}$ feather values, showing that to some extent these birds return to the same geographic region or ecologically similar moulting areas from year to year. We used a separate dataset of individuals captured across Sweden in two or more years to compare between-year repeatabilities of feather $\delta^{13} \mathrm{C}$ and $\delta^{15} \mathrm{~N}$ values with repeatabilities from our wing feathers that represent the beginning (innermost primary) and end (outermost primary) of the moult sequence of the same individual. By comparing the within-year variation (innermost to outermost primary) with the between-year variation (only the innermost primary), we examine to what extent the unexplained between-year variation can be accounted for by within-year variation. Further, low between-year or withinwing (same year) repeatabilities would suggest low winter habitat or site-fidelity and/or switching diet, while on the other hand high repeatabilities suggests high habitat or sitefidelity and/or a similar diet.

\section{Methods}

\section{Background and sampling}

Passerines typically replace all of their flight feathers and body feathers on an annual basis after breeding and before migration to the wintering grounds or after arrival on the wintering grounds (Svensson 1992, Pyle 1997). Flight feather replacement occurs in a fixed sequence that coincides with the replacement of the entire feather coat (Ginn and Melville 1983). For the willow warbler, the post-breeding moult in adults is quite rapid which can result in periods of flightlessness (Haukioja 1971). In addition, all individuals have a second, more protracted complete moult on their African winter-grounds (Underhill et al. 1992). Both complete moults begin with the innermost primary (P1) and ends with the outermost full-sized primary (P9) (Norman 1990, Bensch and Grahn 1993).

We collected 17 adult willow warblers upon return to Sweden from the wintering grounds in Africa in the spring of 2008 from both sides of the migratory divide, i.e. nine 'southern' and eight 'northern', for a separate study on the genetic differences of the two migratypes (Table 1). From the same individuals we salvaged the wings for stable isotope analysis. We used the tips for each of the nine full-sized primary feathers from the left wing of each individual for isotopic analyses. From a separate study on the migratypic differences of trochilus versus acredula, we collected adult willow warbler first primaries from males grown on their wintering grounds in Africa captured on their breeding grounds in Sweden, between 1996 and 2010. Fifty-eight of these individuals were recaptured during this period and were sampled for both $\delta^{13} \mathrm{C}$ and $\delta^{15} \mathrm{~N}$ (see methods described in Chamberlain et al. 2000 and Bensch et al. 2006).

We collected willow warblers following the ethical guidelines under a permit from Malmö/Lund djurförsöksetiska nämnd, permit number M94-08. Approval for permission for capturing birds came from Swedish Environmental Protection Agency and the Swedish Ringing Centre at the Natural History Museum in Stockholm.

\section{Laboratory analysis}

We prepared $1.0 \pm 0.1 \mathrm{mg}$ of feather material removed from the distal end (the tip) of each primary feather on the left wing from each individual. All samples were loaded into

Table 1. Willow warbler sample size and locations for Sweden by region, coordinates are in WGS84 (decimal degrees).

\begin{tabular}{lccccc}
\hline Site name & Region & $\mathrm{N}$ & Latitude & Longitude & Elevation $(\mathrm{m})$ \\
\hline Anjan & North & 4 & 63.73 & 12.54 & 439 \\
Tångböle & North & 4 & 63.35 & 12.59 & 520 \\
Stensoffa & South & 8 & 55.70 & 13.46 & 17 \\
Vomb & South & 1 & 55.67 & 13.55 & 26 \\
\hline
\end{tabular}


tin cups and analyzed for $\delta^{13} \mathrm{C}$ and $\delta^{15} \mathrm{~N}$ via continuousflow isotope-ratio mass spectrometry (CFIRMS). Specifically, between $0.5\left(\delta^{13} \mathrm{C}\right)$ and $1.0 \mathrm{mg}\left(\delta^{15} \mathrm{~N}\right)$ of material was combusted online using an elemental analyzer. The resulting $\mathrm{CO}_{2}$ and $\mathrm{N}_{2}$ analyte gas from the samples was separated by gas chromatography (GC) and introduced into a triplecollector isotope-ratio mass-spectrometer via an open split and compared to a pure $\mathrm{CO}_{2}$ or $\mathrm{N}_{2}$ reference gas. Stablenitrogen and carbon isotope ratios were expressed in delta $(\delta)$ notation, as parts per thousand (\%) deviations from the primary standards of atmospheric nitrogen and VPDB (Vienna Pee Dee Belemnite carbonate) standards, respectively. Using previously calibrated internal laboratory $\mathrm{C}$ and $\mathrm{N}$ standards (powdered keratin, peagrain and gelatin), within-run precisions for $\delta^{15} \mathrm{~N}$ and $\delta^{13} \mathrm{C}$ were $\sim \pm 0.15 \%$.

\section{Statistical analysis}

We used a general linear mixed model (GLMM) approach to determine the regional differences in $\delta^{13} \mathrm{C}$ and $\delta^{15} \mathrm{~N}$. For this we used the $R$ package $n l m e$ (Pinheiro et al. 2013) to test whether our samples demonstrated the previously described regional differences in winter-grown primary feather $\delta^{15} \mathrm{~N}$ between acredula in the north and trochilus in the south (Chamberlain et al. 2000). Model structure included $\delta^{13} \mathrm{C}$ and $\delta^{15} \mathrm{~N}$ separately (for all nine primaries) as the dependent variables with region as fixed factors and individual as a random factor. Further, we used the same model structure but added the interaction between feather position and region to determine if the variation in $\delta^{13} \mathrm{C}$ and $\delta^{15} \mathrm{~N}$ across the nine primaries differed between regions. To determine if feather isotope values were correlated with primary position across all nine primary feathers from each individual, we calculated a Pearson's correlation coefficient $(r)$ for feather position and each isotope $\left(\delta^{13} \mathrm{C}\right.$ and $\left.\delta^{15} \mathrm{~N}\right)$ separately. We plotted $r$ for both $\delta^{13} \mathrm{C}$ and $\delta^{15} \mathrm{~N}$ with $\alpha=0.05$ levels of significance to identify relationships between stable isotope values and feather position. In addition, we plotted the effect size $(r)$ with corresponding confidence intervals for each individual to evaluate the strength of the correlation between feather position and feather isotopes $\left(\delta^{13} \mathrm{C}\right.$ and $\left.\delta^{15} \mathrm{~N}\right)$ and the confidence in interpreting the effect (Nakagawa and Cuthill 2007). Next, we calculated the repeatability or intraclass correlation coefficient (R) using the $R$ package ICC (Wolak 2011), for both isotopes measured across the tips of the tips of P1 (innermost) and P9 (outermost) primary flight feathers. The first and last primaries represent the start and end points of an individual's moult and thus represent the extremes of the moult period. For this repeatability analysis we used a two-way ANOVA (Shrout and Fleiss 1979, Lessells and Boag 1987), as implemented in the psych R package (Revelle 2012), with feather position as a fixed effect to subdivide the total variability into three components, 1) between-individual, 2) between-feather position, and 3) the residual to determine the intraclass correlation coefficient (Shrout and Fleiss 1979). For comparison, we calculated between-year repeatabilities with a separate Swedish willow warbler dataset (1996 and 2010). Here we used only the first primary (P1) for between-year samples from the same individual. Between-year samples $(n=58)$ allowed us to compare annual differences in habitat use or diet. Finally, we then compared the repeatabilities to determine whether $\mathrm{R}$ was lower or higher within the
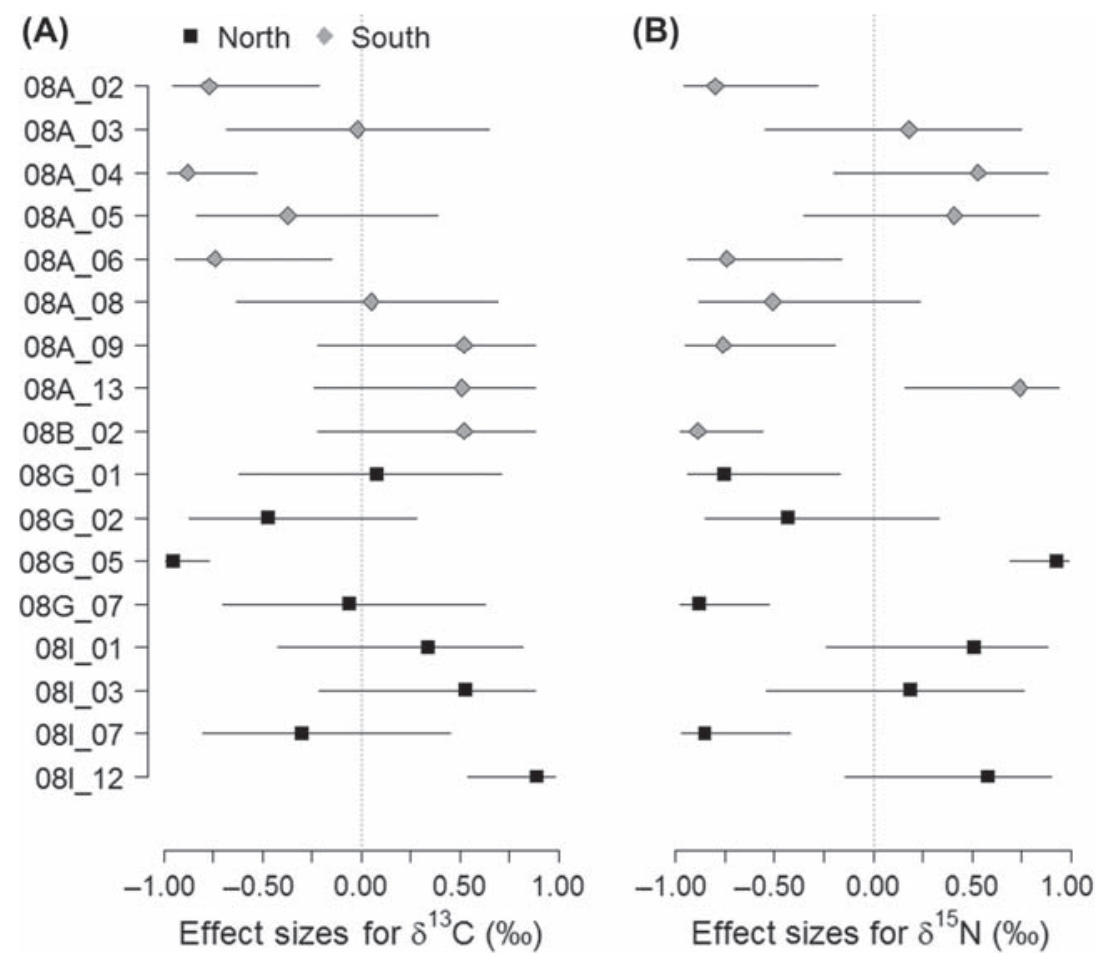

Figure 1. Effect sizes (correlation coefficient) with $95 \%$ confidence intervals for both (A) $\delta^{13} \mathrm{C}$ and (B) $\delta^{15} \mathrm{~N}$ and primary feather position (1 to 9) for willow warbler winter grown feathers in Africa that were sampled in the north and south of Sweden. 
same moult episode (P1/P9, wing dataset) compared to the same feather (P1, 1996 to 2010 dataset) in different moult episodes (i.e. between years).

All analyses were performed in $R$ ver. 2.14.

\section{Results}

We found significant differences in winter-grown primary feather $\delta^{15} \mathrm{~N} \quad\left(\mathrm{~T}_{15}=-2.61, \mathrm{SE}=0.90, \mathrm{p}=0.01\right)$, but not $\delta^{13} \mathrm{C}\left(\mathrm{T}_{15}=-0.16, \mathrm{SE}=0.79, \mathrm{p}=0.87\right)$ between southern trochilus that winters in west Africa and northern acredula wintering in east or south Africa. The mean estimates for $\delta^{15} \mathrm{~N}$ values ( \pm SD) were $7.4 \pm 1.1 \%$ o for trochilus and $10.0 \pm 2.4 \%$ for acredula. The corresponding estimates for $\delta^{13} \mathrm{C}$ were $-21.28 \pm 1.3 \%$ o for trochilus and $-21.27 \pm 1.4 \%$ o for acredula. Further, we did not find any differences in the within individual variation across primaries 1 to 9 in $\delta^{15} \mathrm{~N}$ between regions $\left(T_{15}=-1.24\right.$, $\mathrm{SE}=0.10, \mathrm{p}=0.22)$, nor did we find any differences in the within individual variation in $\delta^{13} \mathrm{C}$ between regions $\left(\mathrm{T}_{15}=-1.73, \mathrm{SE}=0.12, \mathrm{p}=0.08\right)$. Fourteen individual's showed significant $\delta^{13} \mathrm{C}$ or $\delta^{15} \mathrm{~N}$ correlations across the primary feathers demonstrating consistent changes in isotopic values from the innermost to the outermost feather. These included three trochilus (all positive) and two acredula (one positive and one negative) for $\delta^{13} \mathrm{C}$ (Supplementary material Appendix A1, Table A1) and five trochilus (four positive and one negative) and four acredula (three positive and one negative) for $\delta^{15} \mathrm{~N}$ (Supplementary material Appendix A1, Table A2, Fig. 1A, B). Seven of the later individuals revealed significant negative and two positive correlations for $\delta^{15} \mathrm{~N}$ and four showed significant negative and one positive for $\delta^{13} \mathrm{C}$; one of these individuals was significant for both isotopes. Of these 14 individuals, inspection of effect sizes and confidence intervals (Supplementary material Appendix A1, Table A1, A2, Fig. 1A, B) demonstrated that only seven of these individuals had confidence intervals that did not overlap zero, supporting that these individuals from both subspecies likely changed their diet or habitats during moult.

Repeatability analyses based on all nine primaries were significant and similar in both the north and south. Repeatability analyses based only on the innermost (P1) and the outermost (P9) primary was significant for $\delta^{15} \mathrm{~N}$ in both regions, but significant for $\delta^{13} \mathrm{C}$ only in the north (Table 2). For the separate dataset representing between-year captures of the same individuals, repeatability analysis of the innermost primary (P1) for both $\delta^{13} \mathrm{C}$ and $\delta^{15} \mathrm{~N}$ were significant (Table 3). There were wide confidence intervals with moderate effect sizes for within-year (both for comparing P1 and P9). When we analysed the effect sizes for the repeatabil- ity of between-year samples ( $\mathrm{P} 1$ only) for $\delta^{13} \mathrm{C}$, we found a strong effect size with narrow confidence intervals (Fig. 2). The same analyses for $\delta^{15} \mathrm{~N}$ resulted in moderate effect size with wider confidence intervals (Fig. 2).

\section{Discussion}

Here we analyzed wing feather stable isotope $\left(\delta^{13} \mathrm{C}, \delta^{15} \mathrm{~N}\right)$ patterns from two willow warbler subspecies with distinctly different wintering areas to investigate population-specific adaptations and ecology during the wintering moult period in Africa, which is an important, but little known part of the annual cycle. We found that in $41 \%$ of the individuals the primary feather $\delta^{13} \mathrm{C}$ and $\delta^{15} \mathrm{~N}$ values changed significantly across the wing from the innermost to the outermost primary feather suggesting a shift in diet, habitat, or location during the winter moult. Contrary to our predictions that trochilus in west Africa would likely show increasing $\delta^{13} \mathrm{C}$ and $\delta^{15} \mathrm{~N}$ values from the innermost to the outermost feather in response to conditions becoming drier during the moulting period; the observed changes were neither consistent among individuals nor subspecies.

Willow warblers occur in a wide range of habitats across sub-Saharan Africa (Herremans 1997, Salewski and Jones 2006, Jones et al. 2010). The use of these habitats varies temporally with changes in densities recorded throughout the wintering period and across their range, suggesting intracontinental movements or 'itinerancy' (Jones et al. 2010). Many species of Palaearctic-Afrotropical migrants, including willow warblers, track the rains associated with the Intertropical Convergence Zone (ITCZ) as it shifts south after the summer rains and then moves back north in the spring (Moreau 1972, Jones et al. 1998, Salewski et al. 2002). Presumably as local habitats dry out and food resources become scare, many individual songbird migrants have to intensify their foraging movements in order to track available resources at different times (Jones et al. 1998, Salewski and Jones 2006).

In west Africa, the drying out occurs between December and March coincident with trochilus winter moult (Williamson 1962, Underhill et al. 1992, Salewski et al. 2004). For trochilus the winter moult of the outermost primary occurs approximately six weeks later than the innermost primary as habitats continuously become dryer. Given these conditions, one might expect $\delta^{13} \mathrm{C}$ and $\delta^{15} \mathrm{~N}$ values to increase if they follow the general patterns for how these isotopes respond to increasingly arid climate conditions (Rubenstein and Hobson 2004). Although isotopic patterns changed across the wing for six individuals, the direction of change was both towards higher and lower values. Hence, this suggests that the starting date of moult cannot explain the between-individual-variation in isotope values of the innermost primary. Our results indi-

Table 2. Repeatability analysis for two subspecies of willow warblers in the north and south of Sweden reporting the intraclass correlation coefficients (R) for $\delta^{13} \mathrm{C}$ and $\delta^{15} \mathrm{~N}$ values in the tips of P1 (innermost) and P9 (outermost) primary flight feathers.

\begin{tabular}{lcccccccrr}
\hline Region & Isotope & DF & SS & MS & $F$ & $p$ & $R$ & lower Cl & upper Cl \\
\hline North & $\delta^{13} \mathrm{C}$ & 7 & 75.34 & 10.76 & 5.47 & 0.020 & 0.69 & 0.05 & 0.93 \\
South & ${ }^{13} \mathrm{C}$ & 8 & 25.38 & 3.17 & 1.89 & 0.194 & 0.31 & -0.40 & 0.79 \\
North & ${ }^{15} \mathrm{~N}$ & 7 & 93.93 & 13.42 & 4.70 & 0.029 & 0.65 & -0.03 & 0.92 \\
South & ${ }^{15} \mathrm{~N}$ & 8 & 19.11 & 2.39 & 5.11 & 0.017 & 0.67 & 0.07 & 0.92 \\
\hline
\end{tabular}


Table 3. Willow warbler repeatability analysis reporting the intraclass correlation coefficients (R) for $\delta^{13} \mathrm{C}$ and $\delta^{15} \mathrm{~N}$ values in primary flight feathers (P1) of individuals captured in different years $(n=58)$. Data collected between 1996 and 2011.

\begin{tabular}{lcccccccc}
\hline Isotope & DF & SS & MS & $F$ & $p$ & $R$ & $\mathrm{Cl}$ & $\mathrm{Cl}$ \\
\hline$\delta^{13} \mathrm{C}$ & 57 & 259.17 & 4.55 & 2.45 & $<0.001$ & 0.42 & 0.18 & 0.61 \\
$\delta^{15} \mathrm{~N}$ & 57 & 321.84 & 5.65 & 6.11 & $<0.001$ & 0.72 & 0.57 & 0.82 \\
\hline
\end{tabular}

cate the timing of moult for each sequential primary does not have a major or consistent effect on the isotope values. If the alternative was true (consistent change over time) observed differences in isotope values from birds collected at different European breeding sites, could merely reflect different moulting times rather than moulting areas.

The subspecies acredula arrives in east Africa at the onset of the rainy season as the ITCZ moves south, where they encounter moist conditions and a flush of food resources (Moreau 1972, Jones 1995). For these populations the moult period typically occurs between December and April (Williamson 1962, Underhill et al. 1992). In a study to investigate the timing and extent of moult in southern African acredula Underhill et al. (1992) found fewer individuals than expected had completed their moult, a suggestion that the willow warblers also shift locations towards the end of the moulting period. For acredula one might expect $\delta^{13} \mathrm{C}$ and $\delta^{15} \mathrm{~N}$ values to be stable or decline given the prevailing wet conditions during the moult period. However, changes in isotopes occurred in both directions for five individuals. Further, we could find no information available in the literature on possible differences in primary growth rates or in feather quality between the two subspecies during the winter that may impact feather $\delta^{13} \mathrm{C}$ and $\delta^{15} \mathrm{~N}$ values.

The changes in $\delta^{13} \mathrm{C}$ and $\delta^{15} \mathrm{~N}$ for both subspecies in our study may reflect a diet shift or that they supplemented their normal diet of insects with other seasonally abundant resources. For example, Biebach et al. (1986) noted that willow warblers, despite being primarily foliage-gleaning insectivores, consumed berries and other plant materials in Africa. How much feather $\delta^{13} \mathrm{C}$ and $\delta^{15} \mathrm{~N}$ values reflect a shift in diet in these arid regions is unknown. Likewise, the timeintegration for $\delta^{13} \mathrm{C}$ and $\delta^{15} \mathrm{~N}$ into the diet items consumed during feather growth are unknown, e.g. berries or insect biomass might have grown months previous to consumption. However, well-established patterns of $\delta^{15} \mathrm{~N}$ in animal tissues based on switching diet or trophic position do exist (DeNiro and Epstein 1981, Kelly 2000). Repeatability analysis of the innermost and outermost winter grown primaries resulted in similar repeatabilities to our between-year (sameindividual) estimates for both $\delta^{13} \mathrm{C}$ and $\delta^{15} \mathrm{~N}$. Our results suggests that individuals are as faithful to the area where they start moult between years as they are to the area where they complete moult within a year.

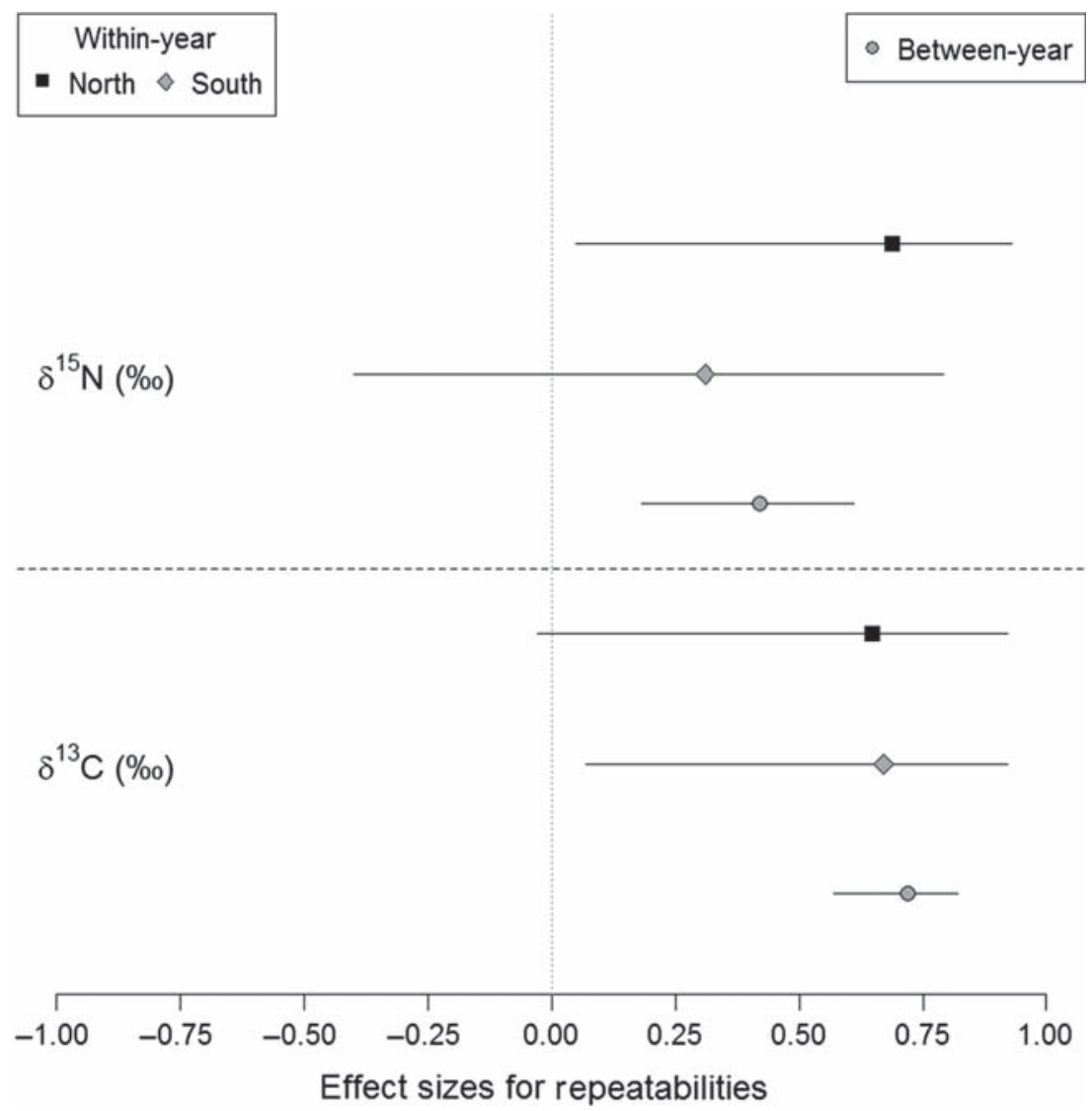

Figure 2. Effect sizes (correlation coefficient) with $95 \%$ confidence intervals given for both $\delta^{13} \mathrm{C}$ and $\delta^{15} \mathrm{~N}$ repeatability analysis for willow warbler winter grown feathers in Africa that were sampled in both the north and south of Sweden. The within-year samples represented by primaries 1 to 9 and between-year samples only primary1. 
Acknowledgements - The willow warblers were sampled with ethical permission from Malmö/Lund djurförsöksetiska nämnd (M94-08) and permission from Naturvårdsverket and the Swedish Ringing Centre for capturing birds. This project was financed by grants from the Swedish Research Council (to SA 621-2007-5930, 621-2010-5584 and SB, 621-2010-5277), a Feodor Lynen fellowship, Alexander von Humboldt-Foundation (ML), and by operating grants to KAH and LIW from Environment Canada. This is a report from the Centre for Animal Movement Research (CAnMove) financed by a Linnaeus grant (349-2007-8690) from the Swedish Research Council and Lund Univ.

\section{References}

Bensch, S. and Grahn, M. 1993. A new method for estimating individual speed of molt. - Condor 95: 305-315.

Bensch, S., Bengtsson, G. and Åkesson, S. 2006. Patterns of stable isotope signatures in willow warbler Phylloscopus trochilus feathers collected in Africa. - J. Avian Biol. 37: 323-330.

Biebach, H., Friedrich, W. and Heine, G. 1986. Interaction of bodymass, fat, foraging and stopover period in trans-Sahara migrating passerine birds. - Oecologia 69: 370-379.

Chamberlain, C. P., Bensch, S., Feng, X., Åkesson, S. and Andersson, T. 2000. Stable isotopes examined across a migratory divide in Scandinavian willow warblers (Phylloscopus trochilus trochilus and Phylloscopus trochilus acredula) reflect their African winter quarters. - Proc. R. Soc. B 267: 43-48.

Cramp, S. and Brooks, D. J. (eds) 1992. The birds of the Western Palearctic. 6. Warblers. - Oxford Univ. Press.

DeNiro, M. J. and Epstein, S. 1981. Influence of diet on the distribution of nitrogen isotopes in animals. - Geochim. Cosmochim. Acta 45: 341-351.

Evans, K. L., Waldron, S. and Bradbury, R. B. 2003. Segregation in the African wintering ranges of English and Swiss swallow Hirundo rustica populations: a stable isotope study: capsule stable isotope analysis of swallow feathers, grown in Africa, revealed significant differences between populations breeding in Switzerland and England. - Bird Study 50: 294-299.

Ginn, H. B. and Melville, D. S. 1983. Molt in birds. - British Trust Ornithol., Tring, UK.

Haukioja, E. 1971. Flightlessness in some moulting passerines in northern Europe. - Ornis Fenn. 48: 101-116.

Hedenström, A. and Pettersson, J. 1987. Migration routes and wintering areas of willow warblers Phylloscopus trochilus (L.) ringed in Fennoscandia. - Ornis Fenn. 64: 137-143.

Herremans, M. 1997. Willow warbler Phylloscopus trochilus. - In: Harrison, J. A., Allan, D. G., Underhill, L. G., Herremans, M., Tree, A. J., Parker, V. and Brown, C. J. (eds), The atlas of southern African birds, Vol. 2, Passerines. BirdLife South Africa, Johannesburg, pp. 254-255.

Hobson, K. A., Van Wilgenburg, S. L., Wassenaar, L. I., Powell, R. L., Still, C. J. and Craine, J. M. 2012. A multi-isotope $\left(\delta^{13} \mathrm{C}, \delta^{15} \mathrm{~N}, \delta^{2} \mathrm{H}\right)$ feather isoscape to assign Afrotropical migrant birds to origins. - Ecosphere 3: art44.

Janowiak, J. E. 1988. An investigation of interannual rainfall variability in Africa. - J. Clim. 1: 240-255.

Jones, P. J. 1995. Migration strategies of Palearctic passerines in Africa. - Isr. J. Zool. 41: 393-406.

Jones, P., Newbery, D. M., Prins, H. H. T. and Brown, N. D. 1998. Community dynamics of arboreal insectivorous birds in African savannas in relation to seasonal rainfall patterns and habitat change. - In: Dynamics of tropical communities: the 37th Symp. of the Br. Ecol. Soc., Cambridge Univ., 1996, pp. 421-447.

Jones, P., Salewski, V., Vickery, J. and Mapaure, I. 2010. Habitat use and densities of co-existing migrant willow warblers Phylloscopus trochilus and resident eremomelas Eremomela spp. in Zimbabwe. - Bird Study 57: 44-55.

Kelly, J. F. 2000. Stable isotopes of carbon and nitrogen in the study of avian and mammalian trophic ecology. - Can. J. Zool. 78: $1-27$.

Lessells, C. M. and Boag, P. T. 1987. Unrepeatable repeatabilities: a common mistake. - Auk 104: 116-121.

Møller, A. P. and Hobson, K. A. 2004. Heterogeneity in stable isotope profiles predicts coexistence of populations of barn swallows Hirundo rustica differing in morphology and reproductive performance. - Proc. R. Soc. B 271: 1355-1362.

Moreau, R. E. 1972. The Palaearctic-African bird migration systems. - Academic Press.

Nakagawa, S. and Cuthill, I. C. 2007. Effect size, confidence interval and statistical significance: a practical guide for biologists. - Biol. Rev. 82: 591-605.

Norman, S. C. 1990. Factors influencing the onset of postnuptial moult in willow warblers Phylloscopus trochilus. - Ringing Migration 11: 90-100.

Pain, D. J., Green, R. E., Gießing, B., Kozulin, A., Poluda, A., Ottosson, U., Flade, M. and Hilton, G. M. 2004. Using stable isotopes to investigate migratory connectivity of the globally threatened aquatic warbler Acrocephalus paludicola. - Oecologia 138: 168-174.

Pinheiro, J., DebRoy, S. and Sarkar, D. 2013. nlme: linear and nonlinear mixed effects models. - R Development Core Team.

Pyle, P. 1997. Identification guide to North American birds, part I. - Slate Creek Press, Bolinas, California.

Revelle, W. 2012. psych: procedures for psychological, psychometric and personality research. - Evanston, IL.

Rubenstein, D. R. and Hobson, K. A. 2004. From birds to butterflies: animal movement patterns and stable isotopes. - Trends Ecol. Evol. 19: 256-263.

Salewski, V. and Jones, P. 2006. Palearctic passerines in Afrotropical environments: a review. - J. Ornithol. 147: 192-201.

Salewski, V., Bairlein, F. and Leisler, B. 2002. Different wintering strategies of two Palearctic migrants in west Africa - a consequence of foraging strategies? - Ibis 144: 85-93.

Salewski, V., Altwegg, R., Erni, B., Falk, K. H., Bairlein, F. and Leisler, B. 2004. Moult of three Palaearctic migrants in their west African winter quarters. - J. Ornithol. 145: 109-116.

Shrout, P. E. and Fleiss, J. L. 1979. Intraclass correlations: uses in assessing rater reliability. - Psychol. Bull. 86: 420-428.

Svensson, L. 1992. Identification guide to European passerines. - Br. Trust for Ornithology, Norfolk, England.

Ulfstrand, S. and Högstedt, G. 1976. How many birds breed in Sweden. - Anser 15: 1-32.

Underhill, L. G., Prys-Jones, R. P., Dowsett, R. J., Herroelen, P., Johnson, D. N., Lawn, M. R., Norman, S. C., Pearson, D. J. and Tree, A. J. 1992. The biannual primary moult of willow warblers Phylloscopus trochilus in Europe and Africa. - Ibis 134: 286-297.

Williamson, K. 1962. Identification for ringers: the genus Phylloscopus, 1967th edition. - Holywell Press, Oxford, England.

Wolak, M. 2011. ICC: Functions facilitating the estimation of the intraclass correlation coefficient. $-<$ http://dirk.eddelbuettel. com/cranberries/2012/12/17/\#bda_2.0.12-17>. 